\title{
Controlling SSSC by Full Order State Feedback Controller
}

\author{
Susmita Paul \\ Tripura University \\ Agartala, Tripura (West) \\ Tripura, India
}

\author{
Mukut Datta \\ Tripura University \\ Belonia, Tripura (South) \\ Tripura, India
}

\author{
Champa Nandi, PhD \\ Tripura University \\ Agartala, Tripura (West) \\ Tripura, India
}

\begin{abstract}
In this Paper a new approach to design a Full Order State Feedback Controller of Voltage Source Converter (VSC) based SSSC is proposed for improving transient stability of the system. Here Full Order State Feedback Controller is designed by using Pole Placement method. This paper also presents a conventional PI-controller for SSSC where the PIcontroller parameters are tuned using Ziegler-Nichols Closed Loop Damped Oscillation method. A detailed comparative analysis is done on the basis of system performance between proposed controller and conventional PI Controller. Simulations have been carried out in MATLAB/SIMULINK Environment.
\end{abstract}

\section{General Terms}

SSSC, Full Order State Feedback Controller, Pole Placement.

\section{Keywords}

SSSC, Full Order State Feedback Controller, Pole Placement, PI-controller, Ziegler-Nichols Closed Loop Damped Oscillation.

\section{INTRODUCTION}

In India, power demand is increasing considerably day by day due to the large population and modernization growth. There are many drawbacks in the quality of power in terms of low power factor, poor power voltage profile, voltage fluctuations etc., which are need to be minimized to shake up power demand. For these reasons, improvement in the capability of power transfer of existing power systems is very important [1].

For improving the capability of power transfer of the existing power systems Power Electronics based Flexible AC Transmission System (FACTS) devices have been developed [1]. FACTS technology is introduced by EPRI (Electric Power Research Institute) in 1980's [2]. FACTS help to increase the power transfer capacity, controllability and also utilize flexibility of ac transmission systems. Static Synchronous Series Compensator (SSSC) is a member of FACTS controllers, acts as a series compensation device of the FACTS family. It is mainly connected in series with power transmission lines and able to exchange both active and reactive power at its output terminals with an ac power system. The main function of SSSC is to control power flow in transmission lines and improve transient stability of power systems [3], [4].

In this paper tuning of conventional PI-controller is done for obtaining the best values of proportional \& integral gains for SSSC, so that a comparative analysis can be done between the conventional PI-controller \& the proposed Full Order State
Feedback Controller in terms of maximum overshoot \& settling time of the system.

\section{MODELING OF THE SSSC}

SSSC mainly consists of a transformer which is connected in series with the transmission line, a voltage source converter with some semiconductor devices having turn off capability for coupling with the transformer and a direct current capacitor. The DC capacitor operates as an energy storage element by providing a DC voltage support for the converter functions. SSSC injects a voltage in series with transmission lines through this coupling transformer [4]. The figure below shows the schematic diagram of SSSC.

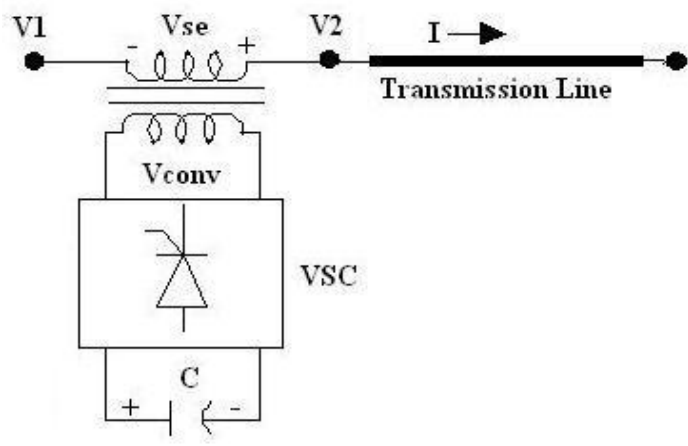

Fig 1: Schematic diagram of SSSC [4]

In this paper the generalized mathematical model of SSSC has been derived.

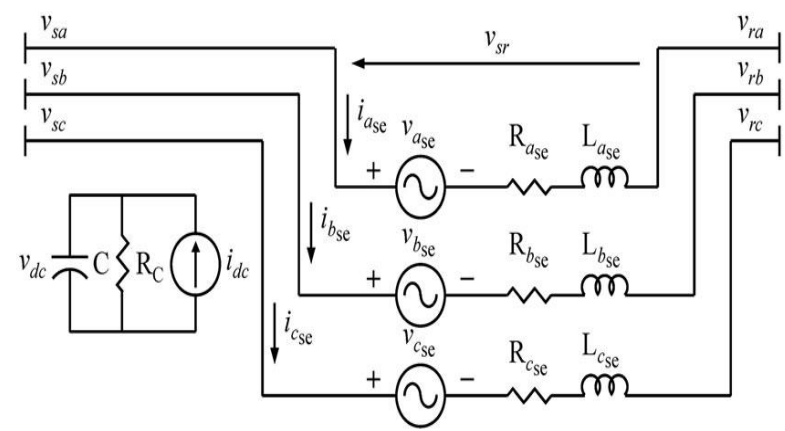

Fig 2: Circuit diagram of SSSC [5]

The circuit diagram of SSSC is shown in fig 2. The dynamic equation from fig 2 can be written as [6]

$\frac{\mathrm{di} \mathrm{i}_{\text {SEa }}}{\mathrm{dt}}=\frac{\mathrm{v}_{\mathrm{Sa}}-\mathrm{V}_{\mathrm{Ra}}}{\mathrm{L}_{\mathrm{SEa}}}-\frac{\mathrm{R}_{\mathrm{SEa}}}{\mathrm{L}_{\mathrm{SEa}}} \mathrm{i}_{\mathrm{SEa}}+\frac{\mathrm{v}_{\mathrm{SEa}}}{\mathrm{L}_{\mathrm{SEa}}}$ 
$\frac{d i_{S E b}}{d t}=\frac{v_{S b}-v_{R b}}{L_{S E b}}-\frac{R_{S E b}}{L_{S E b}} i_{S E b}+\frac{v_{S E b}}{L_{S E b}}$
$\frac{d i_{S E c}}{d t}=\frac{V_{S c}-V_{R c}}{L_{S E c}}-\frac{R_{S E c}}{L_{S E c}} i_{S E c}+\frac{V_{S E c}}{L_{S E c}}$

Where, $\mathrm{i}_{\mathrm{SEa}}, \mathrm{i}_{\mathrm{SEb}}, \mathrm{i}_{\mathrm{SEc}}$ are the series converter (SSSC) currents and $V_{S E a}, V_{S E b}, V_{S E c}$ are the series converter voltages for $a, b$ \& $\mathrm{c}$ phase respectively. $\mathrm{V}_{\mathrm{Sa}}, \mathrm{V}_{\mathrm{Sb}}, \mathrm{V}_{\mathrm{Sc}}$ are the sending end voltages \& $V_{R a}, V_{R b}, V_{R c}$ are the receiving end voltages of the three phase system and $\mathrm{R}_{\mathrm{SEa}}, \mathrm{R}_{\mathrm{SEb}}, \mathrm{R}_{\mathrm{SEc}}$ are the resistances \& $\mathrm{L}_{\mathrm{SEa}}, \mathrm{L}_{\mathrm{SEb}}, \mathrm{L}_{\mathrm{SEc}}$ are the inductances of series converter for $\mathrm{a}, \mathrm{b}$ $\&$ c phase respectively.

The equations (1), (2), (3) can be written in synchronously rotating $d-q$ reference frame as follows [6]

$\frac{\mathrm{di}_{\mathrm{SEd}}}{\mathrm{dt}}=-\frac{\mathrm{R}_{\mathrm{SE}}}{\mathrm{L}_{\mathrm{SE}}} \mathrm{i}_{\mathrm{SEd}}+\omega \mathrm{i}_{\mathrm{SEq}}+\frac{\left(\mathrm{v}_{\mathrm{Sd}}-\mathrm{V}_{\mathrm{Rd}}\right)}{\mathrm{L}_{\mathrm{SE}}}+\frac{\mathrm{v}_{\mathrm{SEd}}}{\mathrm{L}_{\mathrm{SE}}}$

$\frac{\mathrm{di}_{\mathrm{SEq}}}{\mathrm{dt}}=-\omega \mathrm{i}_{\mathrm{SEd}}-\frac{\mathrm{R}_{\mathrm{SE}}}{\mathrm{L}_{\mathrm{SE}}} \mathrm{i}_{\mathrm{SEq}}+\frac{\left(\mathrm{v}_{\mathrm{Sq}}-\mathrm{V}_{\mathrm{Rq}}\right)}{\mathrm{L}_{\mathrm{SE}}}+\frac{\mathrm{v}_{\mathrm{SEq}}}{\mathrm{L}_{\mathrm{SE}}}$

Since for normal operation of the converter, the dc voltage across the dc storage capacitor $\mathrm{C}$ must be kept constant.

$\frac{d V_{d c}}{d t}=\frac{3}{2 C V_{d c}}\left(V_{S E d} i_{S E d}+V_{S E q} i_{S E q}\right)-\frac{V_{d c}}{R_{P} C}$

The magnitude of converter voltage and dc voltage across capacitor are proportional to each other.

$\mathrm{V}_{\mathrm{SEd}}=\left(\mathrm{m}_{\mathrm{SE}} \cos \delta_{\mathrm{SE}}\right) \mathrm{V}_{\mathrm{dc}}$

$\mathrm{V}_{\mathrm{SEq}}=-\left(\mathrm{m}_{\mathrm{SE}} \sin \delta_{\mathrm{SE}}\right) \mathrm{V}_{\mathrm{dc}}$

Here, $m_{S E}$ is the modulation index of SSSC and $\delta_{\mathrm{SE}}$ is phase angle difference between converter voltage $\&$ dc voltage.

Now rewriting equations (4), (5), (6) by substituting equation (7) in matrix form as:

$\frac{d}{d t}\left[\begin{array}{c}i_{S E d} \\ i_{S E q} \\ V_{d c}\end{array}\right]=$

$\left[\begin{array}{ccc}-\frac{\mathrm{R}_{\mathrm{SE}}}{\mathrm{L}_{\mathrm{SE}}} & \omega & \frac{\mathrm{m}_{\mathrm{SE}} \cos \delta_{\mathrm{SE}}}{\mathrm{L}_{\mathrm{SE}}} \\ -\omega & -\frac{\mathrm{R}_{\mathrm{SE}}}{\mathrm{L}_{\mathrm{SE}}} & -\frac{\mathrm{m}_{\mathrm{SE}} \sin \delta_{\mathrm{SE}}}{\mathrm{L}_{\mathrm{SE}}} \\ \frac{3}{2 \mathrm{C}}\left(\mathrm{m}_{\mathrm{SE}} \cos \delta_{\mathrm{SE}}\right) & -\frac{3}{2 \mathrm{C}}\left(\mathrm{m}_{\mathrm{SE}} \sin \delta_{\mathrm{SE}}\right) & -\frac{1}{\mathrm{R}_{\mathrm{P}} \mathrm{C}}\end{array}\right]\left[\begin{array}{c}\mathrm{i}_{\mathrm{SEd}} \\ \mathrm{i}_{\mathrm{SEq}} \\ \mathrm{V}_{\mathrm{dc}}\end{array}\right]+$

$\left[\begin{array}{cc}\frac{1}{\mathrm{~L}_{\mathrm{SE}}} & 0 \\ 0 & \frac{1}{\mathrm{~L}_{\mathrm{SE}}} \\ 0 & 0\end{array}\right]\left[\begin{array}{l}\left(\mathrm{V}_{\mathrm{Sd}}-\mathrm{V}_{\mathrm{Rd}}\right) \\ \left(\mathrm{V}_{\mathrm{Sq}}-\mathrm{V}_{\mathrm{Rq}}\right)\end{array}\right]$

The linearized state equation of SSSC about the operating point $\delta_{0}$ [7]

$$
\begin{aligned}
& {\left[\begin{array}{c}
\Delta \mathrm{l}_{\mathrm{SEd}} \\
\Delta \mathrm{l}_{\mathrm{SEq}} \\
\Delta \dot{\mathrm{V}}_{\mathrm{dc}}
\end{array}\right]\left[\begin{array}{ccc}
-\frac{\mathrm{R}_{\mathrm{SE}}}{\mathrm{L}_{\mathrm{SE}}} & \omega & \frac{\mathrm{m}_{\mathrm{SE}}}{\mathrm{L}_{\mathrm{SE}}} \cos \delta_{0} \\
-\omega & -\frac{\mathrm{R}_{\mathrm{SE}}}{\mathrm{L}_{\mathrm{SE}}} & -\frac{\mathrm{m}_{\mathrm{SE}}}{\mathrm{L}_{\mathrm{SE}}} \sin \delta_{0} \\
\frac{3 \mathrm{~m}_{\mathrm{SE}}}{2 \mathrm{C}} \cos \delta_{0} & -\frac{3 \mathrm{~m}_{\mathrm{SE}}}{2 \mathrm{C}} \sin \delta_{0} & -\frac{1}{\mathrm{R}_{\mathrm{p}} \mathrm{C}}
\end{array}\right]\left[\begin{array}{c}
\Delta \mathrm{i}_{\mathrm{SEd}} \\
\Delta \mathrm{i}_{\mathrm{SEq}} \\
\Delta \mathrm{V}_{\mathrm{dc}}
\end{array}\right]+} \\
& {\left[\begin{array}{ccc}
\frac{1}{\mathrm{~L}_{\mathrm{SE}}} & 0 & -\frac{\mathrm{m}_{\mathrm{SE}}}{\mathrm{L}_{\mathrm{SE}}} \mathrm{V}_{\mathrm{dc}_{0}} \sin \delta_{0} \\
0 & \frac{1}{\mathrm{~L}_{\mathrm{SE}}} & -\frac{\mathrm{m}_{\mathrm{SE}}}{\mathrm{L}_{\mathrm{SE}}} \mathrm{V}_{\mathrm{dc}_{0}} \cos \delta_{0} \\
0 & 0 & -\frac{3 \mathrm{~m}_{\mathrm{SE}}}{2 \mathrm{C}}\left(\mathrm{i}_{\mathrm{SEd}} \sin \delta_{0}+\mathrm{i}_{\mathrm{SEq}} \cos \delta_{0}\right)
\end{array}\right]\left[\begin{array}{c}
\Delta\left(\mathrm{V}_{\mathrm{Sd}}-\mathrm{V}_{\mathrm{Rd}}\right) \\
\Delta\left(\mathrm{V}_{\mathrm{Sq}}-\mathrm{V}_{\mathrm{Rq}}\right) \\
\Delta \delta
\end{array}\right]}
\end{aligned}
$$

The steady state operation of SSSC can be done, by setting all derivative terms of its dynamic mathematical model to zero \& assuming: $\left(V_{S d}-V_{R d}\right)=\left(V_{S}-V_{R}\right),\left(V_{S q}-V_{R q}\right)=0, i_{S E d}=$ $\mathrm{I}_{\mathrm{SEd}}, \mathrm{i}_{\mathrm{SEq}}=\mathrm{I}_{\mathrm{SEq}}$. Rewriting $\omega \mathrm{L}_{\mathrm{SE}}$ as $\mathrm{X}_{\mathrm{SE}}$ steady state equation becomes [8]

$$
\begin{aligned}
& {\left[\begin{array}{ccc}
-\mathrm{R}_{\mathrm{SE}} & \mathrm{X}_{\mathrm{SE}} & \mathrm{m}_{\mathrm{SE}} \cos \delta_{\mathrm{SE}} \\
-\mathrm{X}_{\mathrm{SE}} & -\mathrm{R}_{\mathrm{SE}} & -\mathrm{m}_{\mathrm{SE}} \sin \delta_{\mathrm{SE}} \\
3 \mathrm{~m}_{\mathrm{SE}} \cos \delta_{\mathrm{SE}} & -3 \mathrm{~m}_{\mathrm{SE}} \sin \delta_{\mathrm{SE}} & -\frac{2}{\mathrm{R}_{\mathrm{P}}}
\end{array}\right]\left[\begin{array}{c}
\mathrm{I}_{\mathrm{SEd}} \\
\mathrm{I}_{\mathrm{SEq}} \\
\mathrm{V}_{\mathrm{dc}}
\end{array}\right]=} \\
& {\left[\begin{array}{c}
\left(\mathrm{V}_{\mathrm{S}}-\mathrm{V}_{\mathrm{R}}\right) \\
0 \\
0
\end{array}\right]}
\end{aligned}
$$

Solving $\mathrm{I}_{\mathrm{SEd}}, \mathrm{I}_{\mathrm{SEq}}, \mathrm{V}_{\mathrm{dc}}$; we get the expressions as

$$
\begin{aligned}
& \mathrm{I}_{\mathrm{SEd}}=\frac{\mathrm{R}_{\mathrm{SE}}-\frac{3}{2} \mathrm{~m}_{\mathrm{SE}}^{2} \mathrm{R}_{\mathrm{P}} \sin \delta_{\mathrm{SE}}^{2}}{\mathrm{R}_{\mathrm{SE}}^{2}+\mathrm{X}_{\mathrm{SE}}^{2}-\frac{3}{2} \mathrm{R}_{\mathrm{SE}} \mathrm{m}_{\mathrm{SE}}^{2} \mathrm{R}_{\mathrm{P}}}\left(\mathrm{V}_{\mathrm{S}}-\mathrm{V}_{\mathrm{R}}\right) \\
& \mathrm{I}_{\mathrm{SEq}}=\frac{-\mathrm{X}_{\mathrm{SE}}-\frac{3}{2} \mathrm{~m}_{\mathrm{SE}}^{2} \mathrm{R}_{\mathrm{P}} \sin \delta_{\mathrm{SE}} \cos \delta_{\mathrm{SE}}}{\mathrm{R}_{\mathrm{SE}}^{2}+\mathrm{X}_{\mathrm{SE}}^{2}-\frac{3}{2} \mathrm{R}_{\mathrm{SE}} \mathrm{m}_{\mathrm{SE}}^{2} \mathrm{R}_{\mathrm{P}}}\left(\mathrm{V}_{\mathrm{S}}-\mathrm{V}_{\mathrm{R}}\right) \\
& \mathrm{V}_{\mathrm{dc}}=\frac{\frac{3}{2} \mathrm{~m}_{\mathrm{SE}} \mathrm{R}_{\mathrm{P}}\left(\mathrm{R}_{\mathrm{SE}} \cos \delta_{\mathrm{SE}}+\mathrm{X}_{\mathrm{SE}} \sin \delta_{\mathrm{SE}}\right)}{\mathrm{R}_{\mathrm{SE}}^{2}+\mathrm{X}_{\mathrm{SE}}^{2}-\frac{3}{2} \mathrm{R}_{\mathrm{SE}} \mathrm{m}_{\mathrm{SE}}^{2} \mathrm{R}_{\mathrm{P}}}\left(\mathrm{V}_{\mathrm{S}}-\mathrm{V}_{\mathrm{R}}\right)
\end{aligned}
$$

\section{CONTROL OF SSSC}

In this paper for improving the performance of SSSC as well as the system various control strategies have been developed, which can give better results than the conventional PI controller.

\subsection{Proportional-Integral (PI) control}

PI controller is mostly used to minimize the steady state error causing from the P controller. The closed loop system with PI - controller is shown in fig 3 .

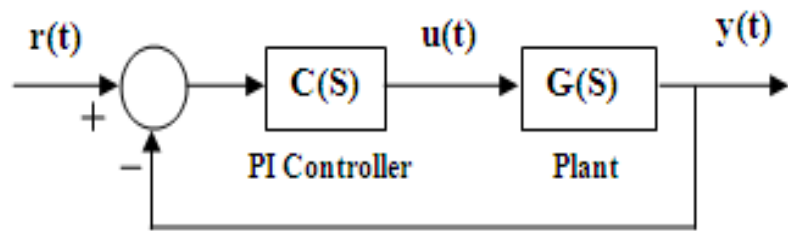

Fig 3: Block diagram for PI - controller based system [9]

To get the most appropriate values for proportional \& integral gain i.e. $\mathrm{K}_{\mathrm{p}}, \mathrm{K}_{\mathrm{i}}$ of the PI - Controller, controller has been tuned using Ziegler-Nichols closed loop damped oscillation method. This method is applicable to those closed loop systems which are not allowed to undergo through sustained oscillations. According to this method, system is initially 
operated with low proportional gain with integral time constant, $\tau_{i} \cong \infty$. The proportional gain is increased slowly till a decay ratio $\left(\mathrm{A}_{2} / \mathrm{A}_{1}\right)$ i.e. the ratio of the amplitudes of subsequent peaks in the same direction is equal to or near about $1 / 4$ is obtained in step response of the output, as shown in fig 4. [9], [10], [11].

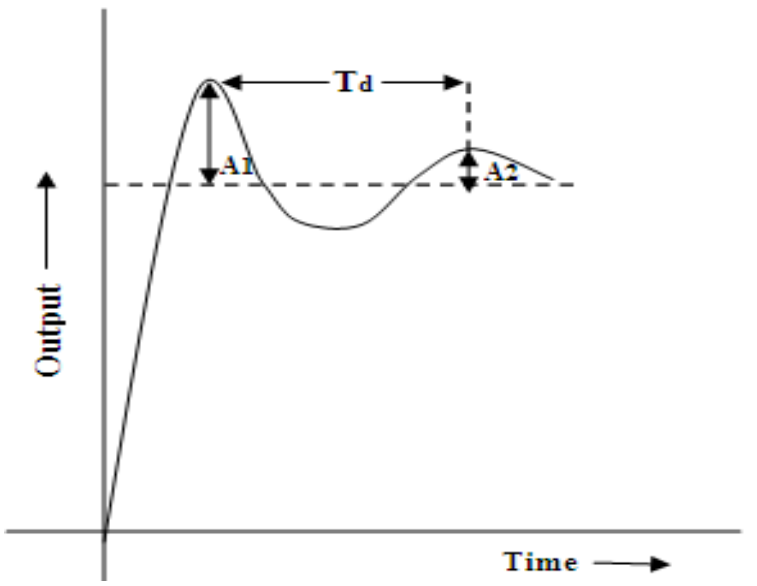

Fig 4: Controller tuning using damped oscillation technique [9]

Under this condition the system is considered as a stable system and the period of damped oscillation, $T_{d}$ is also noted. Let $G_{d}$ be the proportional gain setting for obtaining the desired decay ratio [11]. The optimum setting for a P-I

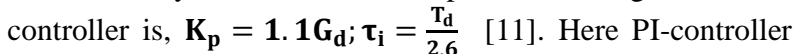
parameters have been tuned for controlling current as well as voltage of SSSC. The block diagram designs of SSSC with PI-controller are shown in fig $5 \& 6$ respectively.

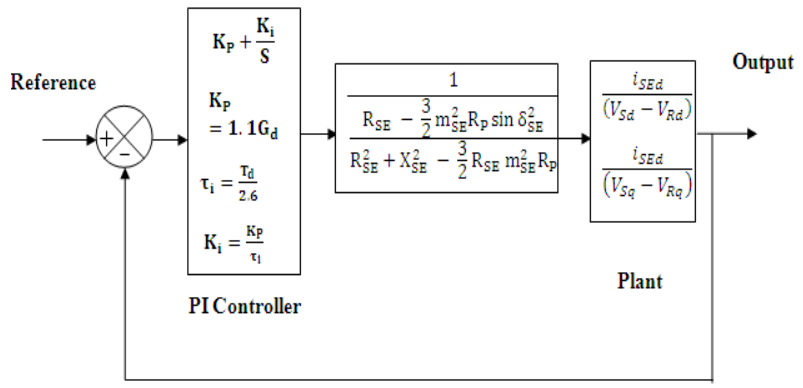

Fig 5: Block diagram of SSSC with PI - controller (current control)

This is the block diagram for controlling current of SSSC; here plant is simply represented by the transfer functions of SSSC:

$$
\begin{aligned}
& \frac{i_{S E d}}{\left(V_{S d}-V_{R d}\right)}= \\
& \frac{2 L_{S E} C R_{P} S^{2}+S\left(2 C_{S E} R_{P}+2 L_{S E}\right)+\left(-3 m_{S E}^{2} \sin \delta^{2} R_{P}+2 R_{S E}\right)}{2 L_{S E}^{2} C R_{P}\left\{\begin{array}{c}
S^{3}+\left(\frac{2 R_{S E}}{L_{S E}}+\frac{1}{R_{P} C}\right) S^{2}+\left(\frac{R_{S E}^{2}}{L_{S E}^{2}}+\frac{2 R_{S E}}{L_{S E} C R_{P}}+\omega^{2}-\frac{3 m_{S E}^{2}}{2 L_{S E} C}\right) S+ \\
\left(\frac{R_{S E}^{2}}{L_{S E}^{2} R_{P}}-\frac{3 m_{S E}^{2} R_{S E}}{2 C L_{S E}^{2}}+\frac{\omega^{2}}{R_{P} C}\right)
\end{array}\right\}}
\end{aligned}
$$

$$
\begin{aligned}
& \frac{i_{\text {SEd }}}{\left(V_{S q}-V_{R q}\right)}=
\end{aligned}
$$

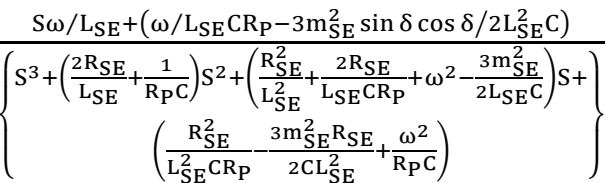

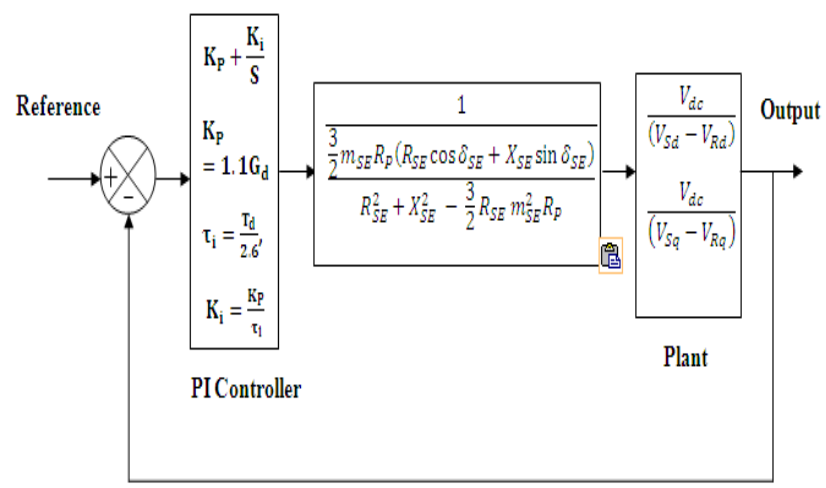

Fig 6: Block diagram of SSSC with PI - controller (voltage control)

This is the block diagram for controlling voltage of SSSC; here also plant is simply represented by the transfer functions of SSSC:

$$
\begin{aligned}
& \frac{\mathrm{V}_{\mathrm{dc}}}{\left(\mathrm{V}_{\mathrm{Sd}}-\mathrm{V}_{\mathrm{Rd}}\right)}=\frac{3 \mathrm{~m}_{\mathrm{SE}} \cos \delta \mathrm{L}_{\mathrm{SE}} \mathrm{S}+3 \omega \mathrm{m}_{\mathrm{SE}} \sin \delta \mathrm{L}_{\mathrm{SE}}+3 \mathrm{~m}_{\mathrm{SE}} \cos \delta \mathrm{R}_{\mathrm{SE}}}{2 \mathrm{~L}_{\mathrm{SE}}^{2} \mathrm{C}\left\{\begin{array}{c}
\mathrm{S}^{3}+\left(\frac{2 \mathrm{R}_{\mathrm{SE}}}{\mathrm{L}_{\mathrm{SE}}}+\frac{1}{\mathrm{R}_{\mathrm{P}} \mathrm{C}}\right) \mathrm{S}^{2}+ \\
\left(\frac{\mathrm{R}_{\mathrm{SE}}^{2}}{\mathrm{~L}_{\mathrm{SE}}^{2}}+\frac{2 \mathrm{R}_{\mathrm{SE}}}{\mathrm{L}_{\mathrm{SE}} \mathrm{CR}_{\mathrm{P}}}+\omega^{2}-\frac{3 \mathrm{~m}_{\mathrm{SE}}^{2}}{2 \mathrm{~L}_{\mathrm{SE}} \mathrm{C}}\right) \mathrm{S}+ \\
\left(\frac{\mathrm{R}_{\mathrm{SE}}^{2}}{\mathrm{~L}_{\mathrm{SE}}^{2} \mathrm{CR}_{\mathrm{P}}}-\frac{3 \mathrm{~m}_{\mathrm{SE}}^{2} \mathrm{R}_{\mathrm{SE}}}{2 \mathrm{CL}_{\mathrm{SE}}^{2}}+\frac{\omega^{2}}{\mathrm{R}_{\mathrm{P}} \mathrm{C}}\right)
\end{array}\right\}} \\
& \frac{\mathrm{V}_{\mathrm{dc}}}{\left(\mathrm{V}_{\mathrm{Sq}}-\mathrm{V}_{\mathrm{Rq}}\right)}= \\
& -3 \mathrm{~m}_{\mathrm{SE}} \sin \delta \mathrm{L}_{\mathrm{SE}} \mathrm{S}+3 \omega \mathrm{m}_{\mathrm{SE}} \cos \delta \mathrm{L}_{\mathrm{SE}}-3 \mathrm{~m}_{\mathrm{SE}} \sin \delta \mathrm{R}_{\mathrm{SE}} \\
& 2 \mathrm{~L}_{\mathrm{SE}}^{2} \mathrm{C}\left\{\begin{array}{c}
\mathrm{S}^{3}+\left(\frac{2 \mathrm{R}_{\mathrm{SE}}}{\mathrm{L}_{\mathrm{SE}}}+\frac{1}{\mathrm{R}_{\mathrm{P}} \mathrm{C}}\right) \mathrm{S}^{2}+ \\
\left(\frac{\mathrm{R}_{\mathrm{SE}}^{2}}{\mathrm{~L}_{\mathrm{SE}}^{2}}+\frac{2 \mathrm{R}_{\mathrm{SE}}}{\mathrm{L}_{\mathrm{SE}} \mathrm{CR}_{\mathrm{P}}}+\omega^{2}-\frac{3 \mathrm{~m}_{\mathrm{SE}}^{2}}{2 \mathrm{~L}_{\mathrm{SE}} \mathrm{C}}\right) \mathrm{S}+ \\
\left(\frac{\mathrm{R}_{\mathrm{SE}}^{2}}{\mathrm{~L}_{\mathrm{SE}}^{2} \mathrm{CR}_{\mathrm{P}}}-\frac{3 \mathrm{~m}_{\mathrm{SE}}^{2} \mathrm{R}_{\mathrm{SE}}}{2 \mathrm{CL}_{\mathrm{SE}}^{2}}+\frac{\omega^{2}}{\mathrm{R}_{\mathrm{P}} \mathrm{C}}\right)
\end{array}\right\}
\end{aligned}
$$

\subsection{Full order state feedback controller by pole placement method}

Pole placement is a method by which a linear system can be stabilized along with a satisfactory response by placing the closed loop poles into desired locations. The objective of placing the closed loop poles into desired locations is achieved by using State Feedback in which the state vectors of the system are feed backed through a gain matrix as input vectors. So it is obvious in designing State feedback controller, all the states of the system should be available or measureable for feedback. This leads to the design of State Observer System [12] which estimates the states of the system based on the measurements of output variables over a period of time. It is of two kinds - full order and reduced order. Here 
full order state observer system has been considered as it estimates all the states of the system. The block diagram of SSSC with full order state feedback controller is shown in fig 7.

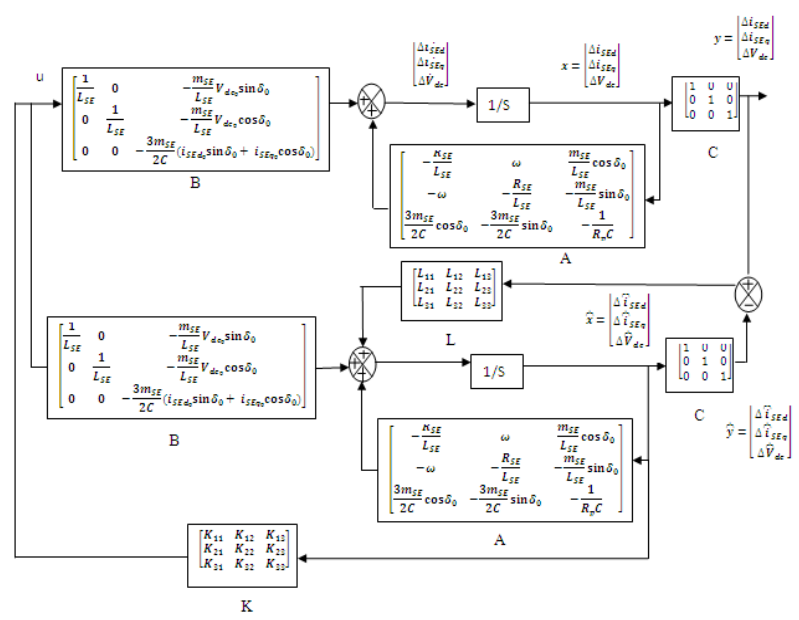

Fig 7: Block Diagram of SSSC with Full Order State Feedback Controller

Open loop system dynamics of the plant can be expressed as

$$
\dot{\mathrm{X}}=\mathrm{AX}+\mathrm{Bu}
$$

As the estimated states are being feed backed, then the control law is

$$
\mathrm{u}=-\mathrm{K} \tilde{\mathrm{X}}
$$

Error dynamics of the observer system is

$$
\dot{\mathrm{E}}=(\mathrm{A}-\mathrm{LC}) \mathrm{E}
$$

Now, combined system dynamics of the whole system is

$$
\left[\begin{array}{l}
\dot{X} \\
\dot{E}
\end{array}\right]=\left[\begin{array}{cc}
A-B K & B K \\
0 & A-L C
\end{array}\right]\left[\begin{array}{l}
X \\
E
\end{array}\right]
$$

So, the characteristic equation of the system is

$|\mathrm{SI}-(\mathrm{A}-\mathrm{BK})||\mathrm{SI}-(\mathrm{A}-\mathrm{LC})|=0$

Here, $\quad|\mathrm{SI}-(\mathrm{A}-\mathrm{BK})|=0$ represents the closed loop characteristic equation for State Feedback Controller \& $|\mathrm{SI}-(\mathrm{A}-\mathrm{LC})|=0$ represents the characteristic equation for State Observer. In order to design the gain matrix $K$ of state feedback controller as well as the gain matrix $L$ of state observer for the system, both the equation need to be solved with the help of desired characteristic equations form by the known desired locations of closed loop poles \& known desired locations of observer poles respectively.

\subsubsection{Determination of closed loop poles}

A well performed system is bounded by maximum limits of settling time $\left(\mathrm{t}_{\mathrm{S}}\right)$ \& maximum overshoot $(\% \mathrm{OS})$ expressed as

$$
\% O S=100 * \mathrm{e}^{\left(\frac{-\xi \pi}{\sqrt{\left(1-\xi^{2}\right)}}\right)} \& \mathrm{t}_{\mathrm{s}}=\frac{4}{\xi \omega_{\mathrm{n}}}
$$

Where, ${ }^{2}$ is damping ratio $\& \omega_{\mathrm{n}}$ is natural frequency [7]. From these values the system desired pole locations are selected as, real part of the system $-\sigma=-\xi \omega_{\mathrm{n}}$
\& imaginary part of the system $\pm \mathrm{j} \omega= \pm \mathrm{j} \omega_{\mathrm{n}} \sqrt{\left(1-\xi^{2}\right)}$

\subsubsection{Determination of observer Eigen values}

The observer Eigen values should be chosen near about ten times faster than the system Eigen values. This can be done by placing the smallest real part of the observer Eigen values ten times bigger than the largest real part of the closed-loop system Eigen values. Therefore,

$\left|\operatorname{Re}\left\{\lambda_{\min }(\mathrm{A}-\mathrm{LC})\right\}\right|_{\text {observer }}>10\left|\operatorname{Re}\left\{\lambda_{\max }(\mathrm{A}-\mathrm{BK})\right\}\right|_{\text {system }}$

\section{CASE STUDY}

The system under consideration is shown in fig 8 .

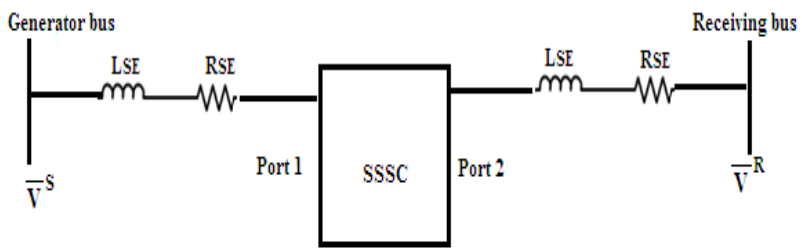

Fig 8: System under study

The system data for SSSC are: [14], [15], [16]

$$
\begin{aligned}
& \mathrm{X}_{\mathrm{SEp.u}}=0.075, \mathrm{R}_{\mathrm{SEp} . \mathrm{u}}=0.0075, \\
& \mathrm{~g}_{\text {capp.u }}=0.02, \mathrm{~b}_{\text {capp.u }}=2 \\
& \mathrm{~m}_{\mathrm{SE}}=0.08, \mathrm{~V}_{\text {Sp.u }}=1.0 \angle 30, \mathrm{~V}_{\mathrm{Rp.u}}=1.0 \angle 0 \\
& \text { Base } \operatorname{MVA}\left(S_{\text {base }}\right)=160 \mathrm{MVA},
\end{aligned}
$$

Base Voltage $\left(V_{\text {base }}\right)=37 \mathrm{KV}$.

\section{SIMULATION RESULTS}

\subsection{Proportional-Integral (PI) control}

By tuning the PI-controller parameters current as well as voltage of SSSC has been controlled.

\subsubsection{Simulation of PI - controller for controlling current of SSSC}

After simulation following results have been found for SSSC: Fig 9.and fig 10.shows the steady state error and output current $i_{d}$ of the system respectively and following parameters have been found after tuning PI-controller as shown in table 1

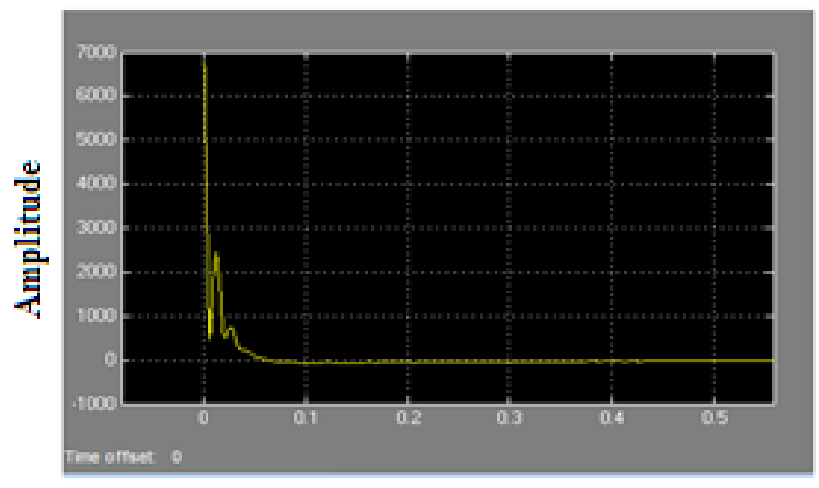

Time

Fig 9: Simulation graph for error signal 


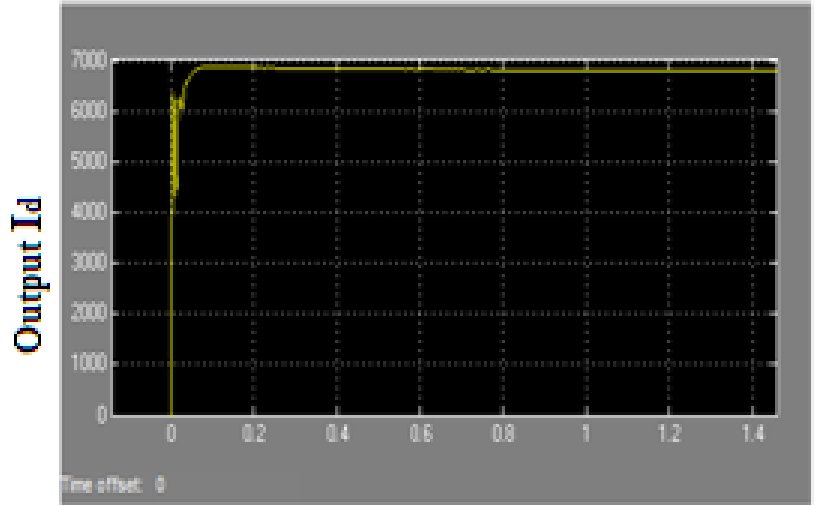

Time

Fig 10: Simulation graph for output current $I_{d}$

Table 1. Parameters obtained after tuning PI-controller for SSSC (controlling current)

\begin{tabular}{|c|c|c|c|c|}
\hline$G_{d}$ & $T_{d}$ & $\tau_{\mathbf{i}}$ & $\mathbf{K}_{\mathbf{P}}$ & $\mathbf{K}_{\mathbf{i}}$ \\
\hline 0.4 & $0.0163 \mathrm{~s}$ & $\begin{array}{l}\tau_{i}=\frac{T_{d}}{2.6} \\
=6.25 \mathrm{e}^{-3}\end{array}$ & $\begin{array}{r}0 \times 1.1 \\
=0.44\end{array}$ & $\begin{array}{l}K_{i}=\frac{K_{p}}{\tau_{i}}= \\
70.4\end{array}$ \\
\hline
\end{tabular}

The system has maximum overshoot, $M_{P} \&$ settling time, $t_{S}$ of $2 \%$ \& 0.09 s respectively.

\subsubsection{Simulation of PI - controller for controlling} voltage of SSSC

Fig 11.and fig 12.shows the steady state error and output voltage $\mathrm{V}_{\mathrm{dc}}$ of the system respectively and following parameters have been found after tuning PI-controller as shown in table 2 .

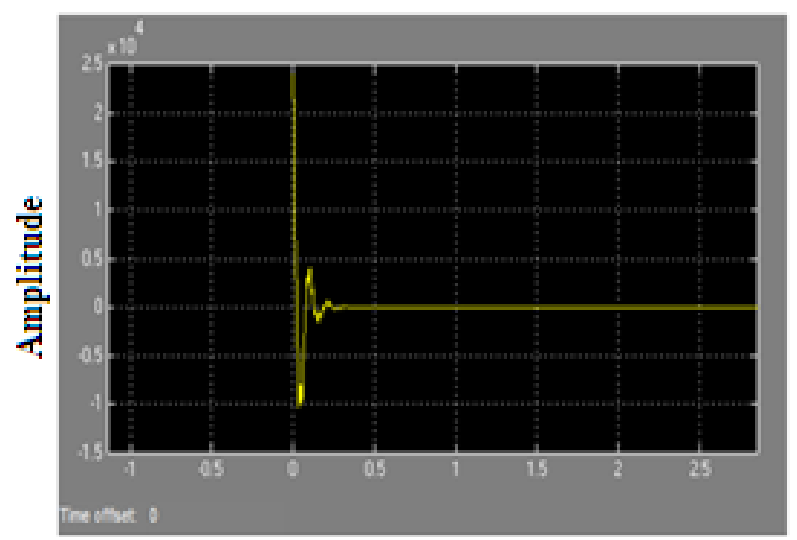

Time

Fig 11: Simulation graph for error signal

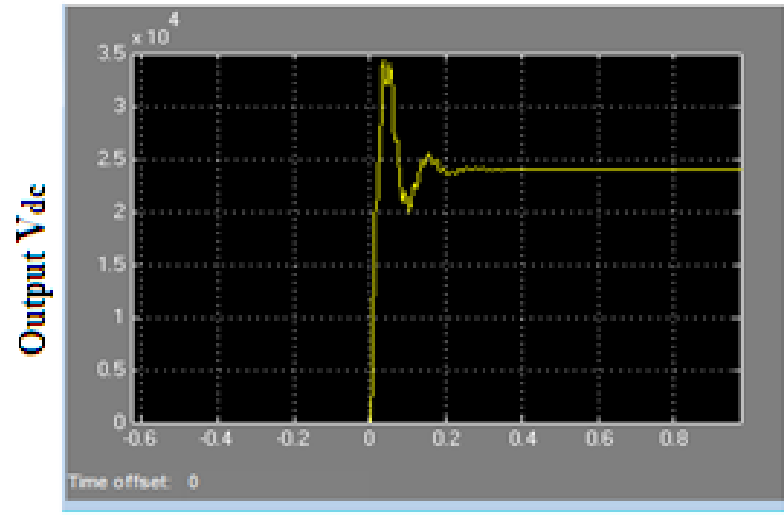

Time

Fig 12: Simulation graph for output voltage $V_{d c}$

Table 2. Parameters obtained after tuning PI-controller for SSSC (voltage current)

\begin{tabular}{|c|c|c|c|c|}
\hline $\mathbf{G}_{\mathbf{d}}$ & $\mathbf{T}_{\mathbf{d}}$ & $\boldsymbol{\tau}_{\mathbf{i}}$ & $\mathbf{K}_{\mathbf{P}}$ & $\mathbf{K}_{\mathbf{i}}$ \\
\hline $\mathbf{0 . 0 9}$ & $\mathbf{0 . 0 2 0 3 \mathrm { s }}$ & $\begin{array}{c}\mathrm{T}_{\mathbf{i}}=\frac{\mathrm{T}_{\mathrm{d}}}{2.6} \\
=7.78 \mathrm{e}^{-3}\end{array}$ & $\begin{array}{c}0.09 \times 1 . \\
=0.099\end{array}$ & $\begin{array}{l}\mathrm{K}_{1}=\frac{\mathrm{K}_{\mathrm{p}}}{\tau_{1}} \\
=12.72\end{array}$ \\
\hline
\end{tabular}

The system has maximum overshoot, $M_{P} \&$ settling time, $t_{S}$ of $41.67 \%$ \& $0.25 \mathrm{~s}$ respectively.

\subsection{Full order state feedback controller by pole placement method}

5.2.1 Determination of closed loop poles for SSSC

The system control specifications i.e. the maximum limits of settling time $\left(t_{s}\right) \&$ maximum overshoot $(\% \mathrm{OS})$ for desired response of the system considered is selected as $0.01 \mathrm{~s} \& 5 \%$ respectively. These result in $-\sigma=-\xi \omega_{\mathrm{n}}=-399.99 \&$ $\pm j \omega= \pm j \omega_{n} \sqrt{\left(1-\xi^{2}\right)}= \pm j 419.48$.

\subsubsection{Determination of observer Eigen values for SSSC}

The observer Eigen values has been chosen by placing the smallest real part of the observer Eigen values ten times bigger than the largest real part of the closed-loop system Eigen values. These result in $-\sigma=10 *-399.99 \&$ $\pm j \omega=10 * \pm j 419.48$.

Fig 13. shows the graph of error signals of the system which means the difference between plant output and observer output. From this fig it can be observed that the error signals of three states are reduced to zero, so the proposed controller can minimize the error.

Fig 14. is the graph of plant states and observer states. From this graph it can be observed that the states of the plant $\left(i_{S E_{d}}, i_{S E_{q}}, V_{d c}\right)$ and the states of observer $\left(i_{S E_{d_{o}}}, i_{S E_{q_{o}}}, V_{d c_{o}}\right)$ converged with each other after some time which means the observer is working properly 
Fig 15.shows the graph of the outputs of the system considering initial conditions for states, $i_{S E_{d_{0}}}=1, i_{S E_{q_{0}}}=$ $-2 \& V_{d c_{0}}=5$. Observations from Fig. 15 are shown in Table 3.

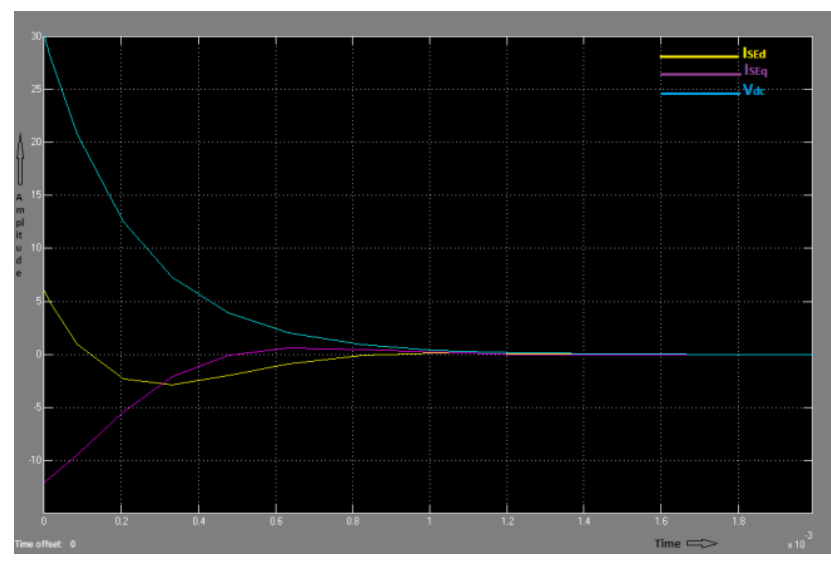

Fig 13: Graph of error signal

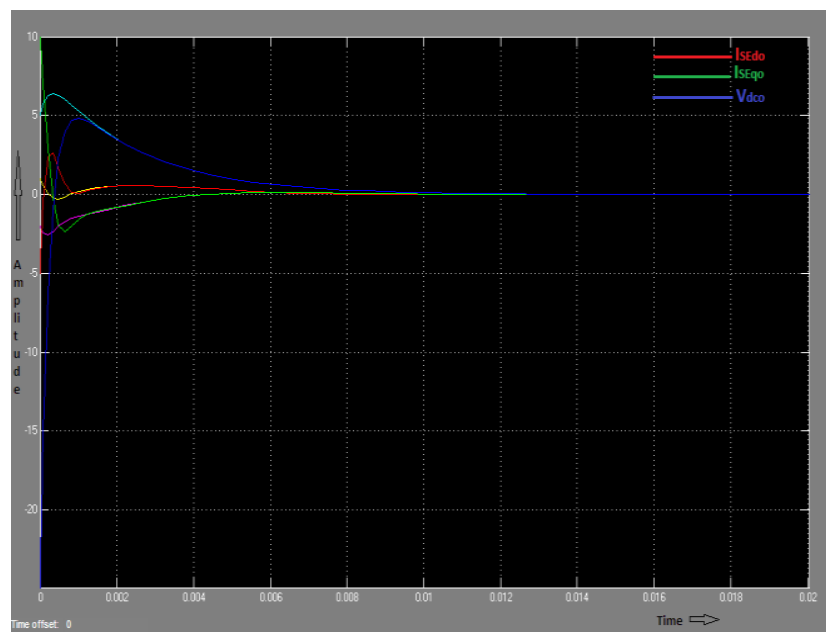

Fig 14: Graph of plant states and observer states

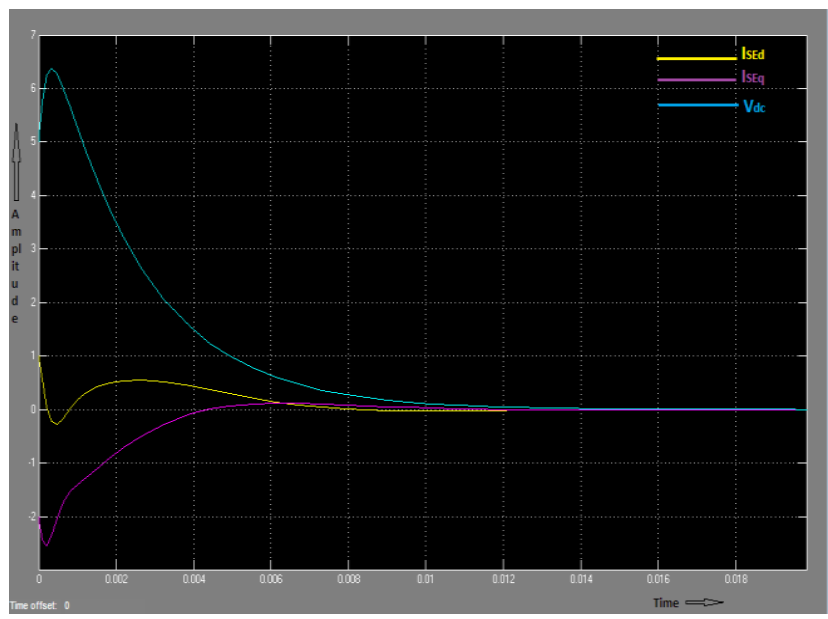

Fig 15: Output graph of SSSC
Table 3: Observations of output signal of SSSC

\begin{tabular}{|c|c|c|}
\hline $\begin{array}{c}\text { System } \\
\text { outputs }\end{array}$ & $\begin{array}{c}\text { Maximum } \\
\text { overshoot }\end{array}$ & Settling time \\
\hline $\boldsymbol{i}_{S E_{d}}$ & $\mathbf{0 . 6 3} \%$ & $0.007 \mathrm{~s}$ \\
\hline $\boldsymbol{i}_{S E_{q}}$ & $\mathbf{0 . 1 8} \%$ & $0.01 \mathrm{~s}$ \\
\hline$V_{d c}$ & $6.45 \%$ & $0.011 \mathrm{~s}$ \\
\hline
\end{tabular}

\section{CONCLUSION}

Increasing energy costs and a greater sensitivity to the environmental impact of new transmission lines demanded the search and application of new controllers to minimise the losses and maximise the stable power transmission capacity of existing lines along with voltage stability. Hence FACTS controllers are becoming an integral component of modern power transmission systems. Controller plays an important role for compensating the system during contingency analysis. This thesis is intended to create an awareness of control issues and has proposed controller for SSSC. In this work first of all a conventional PI controller by proper tuning has been designed for SSSC. The reason behind of tuning is comparative analysis of system performance between the proposed controller and the conventional one.

The research work concentrated on controller design of SSSC. Full order state feedback controller is designed by using Pole Placement method. In this thesis new controller i.e. full order state feedback controller for VSC based SSSC is analyzed and found very effective. It is seen from the simulation result that new proposed controller gives better performance during contingency condition. Besides this, it has been observed from the analysis that the proposed controller is efficient and can provide fast dynamic response to the system than conventional SSSC PI controller.

\section{ACKNOWLEDGMENTS}

Our thanks to the experts who have contributed towards development of the template.

\section{REFERENCES}

[1] J.J Paserba, How FACTS controllers benefits AC transmission system, IEEE transmission on power Engineering Society, Vol.3, sep-2003, pp 949-956.

[2] Ranjit Kumar Bindal, A Review of Benefits of FACTS Devices in Power System, International Journal of Engineering and Advanced Technology (IJEAT), ISSN: 2249 8958, Volume-3, Issue-4, April. 2014.

[3] Laszlo Gyugyi et al. Static Asynchronous Series Compensator: A Solid State Approach to the Series Compensation OF Transmission Lines, IEEE Transactions on Power Delivery ,Vol 12, No. 1, January 1997.

[4] Static Synchronous Series Compensator (SSSC) http://www.powerqualityworld.com/2012/05/sssc-staticsynchronous-series.html.

[5] Images of SSC [online] https://www.google.co.in/search?q=images+of+sssc\&bi $\mathrm{w}=1024 \& \mathrm{bih}=657 \&$ source $=1 \mathrm{nms} \& \mathrm{tbm}=\mathrm{isch} \& \mathrm{sa}=\mathrm{X} \& \mathrm{ved}$ 
$=0$ ahUKEwjvrf7q59TPAhXDRI8KHfLKDfUQ_AUICC $\mathrm{gD}$

[6] Omar H. Abdallaet. al, Unified Power Flow Controller with Decoupled State Feedback, 14th International Middle East Power Systems Conference (MEPCON10), Cairo University,Egypt, December 19-21, 2010, Paper ID 307.

[7] I. J. Nagrath, M. Gopal : Control System Engineering, New Age International Publishers.

[8] Nitus Voraphonpiput and Somchai Chatratana, STATCOM Analysis and Controller Design for Power System Voltage Regulation, Transmission and Distribution Conference \& Exhibition: Asia and PacificDalian, China, 2005 IEEE/PES.

[9] Sena TEMEL, Semih YALI, Semih GREN, P, PD, PI, PID CONTROLLERS, ee402-discrete time control systems recitation 4 report, middle east technical university electrical and electronics engineering department.

[10] http://www.nptel.ac.in/ Module 3, Process Control, Version 2 EE IIT, Kharagpur 1.
[11] Mohammad Shahrokhi and AlirezaZomorrodi, Comparison of PID Controller Tuning Methods, Department of Chemical \& Petroleum Engineering Sharif University of Technology.

[12] NPTEL. A Project funded by MHRD, Govt. of India http://www.nptel.ac.in/

[13] Verica Radisavljevic-Gajic, Linear Observers Design and Implementation, Proceedings of 2014 Zone 1 Conference of the American Society for Engineering Education, 2014.IEEE.

[14] K.R. Padiyar, A.M. Kulkarni, Control Design \& Simulation of Unified Power Flow Controller, IEEE Transactions on Power Delivery, Vol. 13, No. 4, October 1998.

[15] L. Gyugyi, L. Kovalsky A. Keri, A. Mehraban and A. Edris, AEP UPFC Project: Installation, Commissioning and Operation of the +160 MVA STATCOM (PHASE I), IEEE Transactions on Power Delivery, Vol. 13, No. 4 , October 1998.

[16] K.R. Padiyar: FACTS Controllers in Power Transmission and Distribution, New Age International Publishers. 